\title{
Health Workers' Perspectives on Infrastructure to Support Maternal Health Services in Rural Areas of Vietnam
}

\author{
THT Nguyen, A Wilson and F McDonald
}

\begin{abstract}
Background: One common governance issue faced by developing countries is the establishment and maintenance of infrastructure to support the delivery of primary health services. This qualitative study explores the perspective of maternal health workers on how infrastructure impacts the provision of maternity services in rural areas in Vietnam.
\end{abstract}

Methods: Forty-one health workers and health managers at the commune, district and provincial levels of the Vietnamese public health system were interviewed. Questions focused on the impact of various organisational factors, including the impact of infrastructure on the performance of the health workforce, which provides publicly funded primary care. All interviews were recorded, transcribed and coded for thematic analysis.

Findings: Participants noted that infrastructure directly affected their ability to perform certain tasks and could both directly and indirectly negatively impact their motivation. In general, participants noted a lack of investment in infrastructure for the provision of primary care services in rural areas. They identified that there were deficits in the availability of utilities and the adequacy of facilities.

Conclusion: This research contributes to understanding the barriers to the provision of primary care in developing countries and in particular. The current inadequacy of facility buildings and inadequacy of clean water supply are issues for health workers in meeting the technical requirements of the standards as set out in the National Guidelines on reproductive health, and lead to safety concerns for the quality of maternal health services provided in commune health centres and District Health Centres.

Abbreviations: CHC - Commune Health Centres; DHC - District Health Centre; HW - Health Worker.

Key words: infrastructure; health workforce; maternal health services; primary healthcare; Vietnam.

\section{Dr Nguyen Thi Hoai Thu}

Hanoi Medical University

Hanoi, Vietnam.

\section{Professor Andrew Wilson}

Menzies Centre for Health Policy,

University of Sydney,

Sydney, New South Wales, Australia.

\section{Dr Fiona McDonald}

Faculty of Law,

Queensland University of Technology,

Brisbane, Queensland, Australia.

\section{Correspondence:}

nguyenhoaithu@hmu.edu.vn

\section{Background}

Literature shows consensus that developing countries face governance challenges in delivering health services. A common issue is the quality of infrastructure (facilities and utilities) to support the delivery of primary health services. [1] An increasing number of studies identify issues with health infrastructure as barriers to maternal health service utilisation. For example, a recent study conducted in Cambodia found that lack of ward space allowing women to rest after delivery was the main reason that pregnant women did not use maternal health services. [2] As well as buildings, an unreliable supply of utilities, such as electricity and water, can be limiting factors in delivering quality maternal services. $[3,4]$ 
The health system of Vietnam is organised in four layers that parallel the state administration system. The health sector is led by the ministry of health which is on the top level and the other health bodies are underneath. Four levels of publicly funded health services are provided in Vietnam. Primary care is offered through commune health centres ( $\mathrm{CHCs}$ ) in each commune (sub-district) and district health centres (DHCs) in each district. Secondary hospital services are provided at the district level. Each province is divided into approximately 20 districts. Tertiary level hospital facilities are provided at the provincial or national level. See Figure 1.

Recent Vietnamese reports have suggested that investment in physical facilities, resources and equipment for primary healthcare is a priority. $[5,6]$ Investment in primary healthcare in Vietnam remains limited and not all facilities will meet requirements for infrastructure, including clean water and sanitation. [6] Research has demonstrated that poor infrastructure, including physical facilities and utilities demotivates health providers. $[7,8]$ This paper assesses the impact of concerns about infrastructure on the motivation of health workers (HWs) providing primary care services in rural areas in Vietnam. In this paper, maternal health was used as a case study. It is likely that the issues identified in relation to maternal health service delivery will reflect challenges in the broader Vietnamese health system.

\section{Methods \\ Study design}

This study employs qualitative method and data retrieval from local and national health facilities' reports. Participants included $41 \mathrm{HWs}$ and managers from the commune district, and provincial levels. The research focused on five non-urban districts (include two districts in the plain area and others in the mountainous area) from two mountainous provinces in North Vietnam. These provinces are among 15 provinces located in the Northern mountainous area of Vietnam, out of 64 provinces all over the country. The study was part of a larger study examining the governance of maternal health services in rural areas in Vietnam. The data in this was undertaken from January to November 2013.

Figure 1: The organization of health system in Vietnam

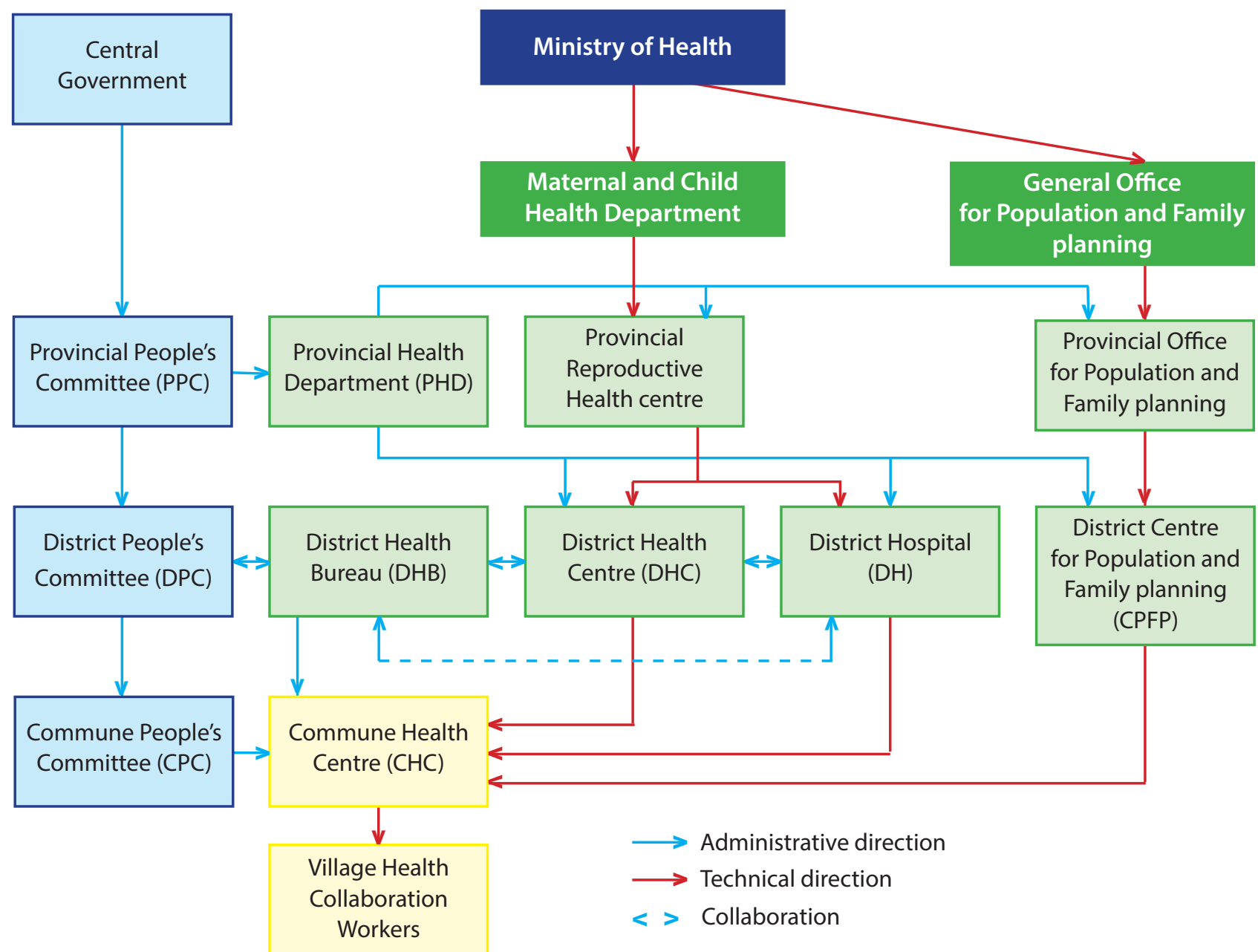




\section{Sampling strategy}

Purposeful sampling was used to select key informants. [9] Apart from purposeful sampling, the approach also involved the 'snow ball' approach with the number of interviews determined by the point that responses to particular questions are saturated, that is, no new information is being added by Strauss and Corbin. [10] Table 1 describes how respondents of each level and facility were selected. Among 41 selected respondents, 20 people were male.

Informed consent was obtained from all individual participants included in the study. Interviews were conducted in Vietnamese by the principal researcher at the HW's or health manager's place of work in a private space and were audio-recorded. In order to ensure maximum variation, participants were selected in terms of health worker categories, different health facilities and gender. [11] Memos and daily field notes were taken that become a part of developing theory and helped to conceptualise the ideas from grounded data. [12] All interviews were conducted in Vietnamese, recorded then checked for quality.

\section{Data analysis}

All interviews were transcribed, coded and analysed using the grounded theory technique with quotations servings as units of analysis. [9] Sources and methods were triangulated by interviewing $\mathrm{HWs}$ and their managers at commune, district, and provincial levels in order to assure the trustworthiness of data. [13] An initial phase of coding on three transcriptions of representative respondents for commune, district and provincial levels were conducted by research team members, using the preliminary coding schedule and also applying grounded theory techniques. [14]

\section{Results}

Both HWs and health managers acknowledged the impact of infrastructure concerns on the performance and motivation of HWs. Key themes that emerged from the analysis were concerns about the availability of utilities and the adequacy of facilities.

\section{Availability of utilities}

Respondents working in a mountainous area in the study provinces reported that electricity was available at almost all CHCs but often they lacked reliable clean water supply. In some $\mathrm{CHCs}$, HWs had to travel some distance to fetch clean water by hand making it difficult to handle a delivery, which raised safety concerns especially in regard to sanitation.

We have a new building; our CHC was established in 2008 so it is quite new. However, our CHC does not meet the National Standards and Guidelines because

Table 1. Sample frame for qualitative study

\begin{tabular}{|c|c|c|c|}
\hline RESPONDENTS/HEALTH FACILITY & QUANTITY & BAC GIANG & LAO CAI \\
\hline Total number of respondents from provincial level & 6 & & \\
\hline Representative of the HR Department, Provincial Health Department & 2 & 1 & 1 \\
\hline Representative of the Provincial Reproductive Health centre & 4 & 2 & 2 \\
\hline Total number of respondents from District level & 26 & & \\
\hline Hospital Manager & 11 & 6 & 5 \\
\hline Manager at district health centre & 9 & 5 & 4 \\
\hline Maternal health worker (obstetric doctor and midwife) & 6 & 3 & 3 \\
\hline Total number of respondents from commune level & 9 & & \\
\hline Head of Commune Health Centre & 4 & 2 & 2 \\
\hline Commune staff & 5 & 3 & 2 \\
\hline Total number of respondents at district and commune levels & & 22 & 19 \\
\hline Total number of respondents: & 41 & & \\
\hline
\end{tabular}


we are lacking clean water. We have to share one water source through a small pipe with the Commune People's Committee and the local school. If there is a delivery, we have to go to fetch water by hand. If woman's relatives are not here, we obviously have to go to get water.

\section{Commune level_Staff_1}

We do not have running water at our $\mathrm{CHC}$. Sometimes we have to catch the rain water for drinking or we have to go the nearest stream that is $1 \mathrm{~km}$ away. To be honest, if a pregnant woman comes to give birth, we do not have water for sanitation.

\section{Communelevel_Manager_1}

Although clean water is a pressing and urgent issue for $\mathrm{CHCs}$ in this district, the solution taken by local authorities to address it appeared largely ineffective.

We reported many times, and every year the District People's Committee provides a plastic or rubbery pipe to bring water to $\mathrm{CHC}$. The pipe is normally an average length of 20-30 meters but there are some places that need a couple of hundred of meters of pipe to go across several hills. The plastic pipe over the hills might be ruined due to buffalos and cows left unbridled during harvesting time.

\section{District level_Manager_1}

Clean water is very important to perform a normal maternal health service at the $\mathrm{CHCs}$. Infrequent or unreliable supplies of clean water in $\mathrm{CHCs}$ in mountainous areas was perceived by participants to have reduced the utilisation of maternal health services as women were reluctant to birth in facilities without water. In addition, clients feel more trust in HWs at the district hospital than at the commune level. The commune health staff recognised the issues, stating, for example:

...patients seek more a trustworthy address. The quality of service in CHC is one of the patients' concerns. Quite few of them bypass to higher levels. In fact, our facility should be upgraded, and health staff should be specialized and appropriately and professionally trained.

\section{Commune level_Manager_3}

Only few patients come to use services. HWs found training less meaningful and effective since there would be no chance for them to practise after training. Though the influence of low service utilisation on staff competence was not explicitly expressed, it was considered to affect HWs, and perceived as a barrier to maintaining the skills of staff in these areas.
It affects us. Because we do not have patients, we cannot practice. We will forget our learnt skills.

Commune level_Staff_3

A lack of utilisation, caused in part by poor infrastructure, was reported to contribute to reducing motivation and morale as HWs were unable to practice their skills.

\section{Adequacy of facilities}

\section{Lack of a permanent building}

After the 2004 reforms, the DHCs were separated from District Hospitals. Despite the fact that this occurred in 2004, ten years later there are still some DHCs that do not have a permanent building. A respondent explained:

Years ago, the district health centre and the district hospital were one. After the separation, the district health centre was not provided with new a building so my $\mathrm{RH}$ department still stays with the hospital. After nearly 10 years, now the hospital needs to have more rooms for development, they take these rooms back so we have to ask the nursery school to stay for some months.

\section{District level_Manager_15}

She expressed concerns about the DHCs situation as they had been asked to leave the nursery school and had no alternative accommodation:

... But if our voice is heard hopefully they would invest money for building infrastructure for a District Health Centre. Not only this District Health Centre, there are several District Health Centres facing similar situations.

This statement was echoed by other district managers, who complained about the inappropriate building of DHC since it was separated from district hospital.

With the infrastructure being downgraded, there's no place for medical equipment if you want to investment in. However, the centre also tried to invest some of equipment, such as the hematological system and the biochemical laboratory. That also meets $70 \%$ of the community's need.

District level_Manager_19

Our place is small, but still better than other centres that are too narrow. I know that one center is borrowing rooms from the district hospital for working, but now the hospital wants to have rooms back, so they have to go somewhere else to work.

District level_Manager_13 
This uncertainty affected performance as HWs could not focus and could not provide safe services in buildings that were temporary and not designed for the provision of health services.

Well, working there [in the nursery school] we never can meet standards in service rooms. Because we just stay there for a short time we cannot build more rooms. There should be an investment in infrastructure for preventive medical care once you intend to develop it so that HWs keep their minds on their work. You know, we are always on the move so we cannot assure infection control.

District level_Manager_15

\section{Size of Facilities}

While some participants were fairly positive about the functionality of their buildings, most reported or acknowledged inadequacies and suggested that these affected staff morale and motivation and performance.

...the second thing is working conditions. Working in a cramped building, commune health workers always claim that we can easily bump into each other when we enter and go outside. It is so small that we cannot do anything, since even the individual working place is not sufficient, it partly decreases staff morale.

Communelevel_Manager_2

The close quarters experienced by HWs affected morale, but also impacted on performance as the space was insufficient to enable HWs to do their jobs effectively. This concern was echoed by a head of an Obstetrics Department who reported it also affected patients:

In fact our hospital infrastructure is very small. Our obstetric department is allocated 25 beds but we do not have enough space. And the staff room, 14 people share only this small room. Please have a look at this room; you can see many clothes and individual property. We keep requesting individual cabinets but do not know where the decision gets stuck so as yet we have not got them. So you see, a dozen staff in this room, so cramped and difficult, and the patient rooms also are not sufficient.

\section{District level_Manager_6}

Another district manager was concerned about his centre's infrastructure and described it as a barrier to service provision and development for the centre.

We have only 210 square meters including toilets. We have to arrange three departments in a room so it is very cramped. The working space is so difficult, so we cannot think of the development of technical services. However we are better than some other district health centres that do not have their own building. So if you want to equip machines you need to have enough space and room, or what can you do?

\section{District level_Manager_13}

\section{Old design of $\mathrm{CHC}$ buildings}

Except for one district that had just invested in rebuilding ten $\mathrm{CHCs}$ that complied with the new infrastructure standards for $\mathrm{CHCs}$, many participants in the other districts in both provinces mentioned that older $\mathrm{CHC}$ buildings were poorly designed and did not meet current standards.

Our CHC was established in 1997. It was built after the pattern of population centre in the past. It has total of six rooms but all rooms share one door and now has been downgraded. Although it is very small, we must reserve two rooms for patients, one room for maternal services and other room for dispensing medicine and also for staff to stay in during night shifts. The common room outside is used for consulting and examination.

\section{Communelevel_Manager_2}

$\mathrm{CHC}$ buildings were funded from local budgets. Commune People's Committees were responsible for the whole process, including building design. It was reported by participants that many buildings did not meet the National Guidelines for CHCs issued in 2011 [15] in terms of numbers of rooms and the design of service rooms. According to the National Guidelines for reproductive health, each $\mathrm{CHC}$ should have six separate rooms (or in some circumstances at least four rooms) for maternal healthcare (gynaecological examination, family planning services, delivery and a patient room). [16] However, most participants from both provinces complained that their $\mathrm{CHCs}$ did not meet these standards.

The development of services is not consistent with the National Guidelines since we lack rooms and have limited medical equipment. Our current infrastructure and medical equipment are very poor. We have a limited number of rooms. Our CHC was designed by Commune People's Committee in the past and they did not follow any pattern for $\mathrm{CHCs}$. So the building of the $\mathrm{CHC}$ depended on the budget of each commune and also on the person in charge of construction work. But it did not follow any pattern.

Communelevel_Manager_3

The shortage of service rooms at $\mathrm{CHCs}$ was reported to lead to room sharing in most $\mathrm{CHCs}$ and this raised concerns about cross contamination and hence about the safety of clients who come to use services in CHCs. Many maternal health services had to be provided in one shared room. 
The delivery attendance, gynaecology examination and family planning services have shared one room for a long time and it caused cross infection from gynaecological patients to women who came to birth or use family planning services. Now we need to separate these rooms. Communelevel_Manager_2,District level_Manager_14

This issue was reported to exist for a long time and explicitly influenced the quality of provided services, the compliance of HWs to the National Guidelines for reproductive health, and therefore the performance of maternal health service providers as well.

It affects us more or less. For example we use one room both for delivery and for gynaecological examination. It involves a sterilisation process. How can we assure infection control?

Communelevel_Staff_2

\section{Discussion}

These qualitative results were consistent with a recent survey conducted by the Department of Maternal and Child Health, Ministry of Health. [17] On average, each CHC in Vietnam has around nine rooms, in which three rooms are used for maternity health services. Maternity health services are among the most important of primary healthcare services at the commune and district levels, however among the vast majority of $\mathrm{CHCs}$ that have rooms set aside for maternal health, the average number of rooms available was only 2.7 (the standard was 4-6 rooms according to the National Guidelines for reproductive health).

Gynecological examination, delivery, and family planning are the three main maternal health services that need to be separated, however according to this report, the proportion of $\mathrm{CHCs}$ that have separate rooms for these services is not high, only $37.8 \%, 34.8 \%$ and $19.0 \%$ respectively. Only $12.6 \%$ of $\mathrm{CHCs}$ have four rooms allocated to maternal health services and so comply with minimum standard set out in the National Guidelines for maternal health. The proportion of $\mathrm{CHCs}$ that have six rooms dedicated to maternal health is much lower. [17] Given the current inadequacy of both facility buildings and clean water supply, there are likely to be issues for HWs in meeting the technical requirements of the standards as set out in the National Guidelines. This affects staff motivation, since HWs reported feeling unsupported and lacking confidence to perform required tasks. It also leads to safety concerns for patients and is said to influence the quality of maternal health services provided in $\mathrm{CHCs}$ and $\mathrm{DHCs}$.
Health facility infrastructure and utility availability are components of working conditions. [18] Herzberg, Mausner and Snyderman [19] suggested that facility infrastructure is what they term a hygiene factor, a factor which by its absence or presence helps determine levels of worker dissatisfaction. The adequacy of infrastructure and the availability of utilities have been identified in previous research as important motivational factors for HWs $[7,20]$ and in maternal health workers in particular. [21] The World Health Organisation has stated that 'no matter how motivated and skilled health workers are, they cannot do their jobs properly in facilities that lack clean water, adequate lighting, heating, vehicles, drugs, working equipment and other supplies.' [1, p.xxii] The literature suggests that deficits in any components related to working conditions will affect not only the quality of health services [22] but also lead to decreased HW job satisfaction and motivation. HWs are motivated by visible improvements in quality of services, [23] so poor working conditions resulting in an inability to provide quality in maternal health services would de-motivate the health workforce.

This research was based on interviews with health managers and Health Workers involved in maternal health services in selected districts in two mountainous Vietnamese provinces. The results thus cannot be generalised to other areas of Vietnam. However, this research is consistent with the broader literature, indicating that Vietnam needs to address issues in relation to infrastructure as part of its efforts to continue to improve primary healthcare. Among participants in this research, it was almost universally acknowledged that the facilities they currently worked in were either too small and did not meet the current requirements, and that this negatively affected their working life both in terms of motivation and their ability to perform required tasks. It was also seen to potentially place patients at risk. Those interviewed for this research associated poor quality facilities with low utilisation by patients, which further contributed to the performance and motivation issues. The study found that HWs report limited investment in infrastructure for primary healthcare in rural areas of Vietnam and as a consequence that facilities may not meet expected standards as set out in the National Guidelines. As a result, rural HWs in Vietnam face continuing challenges to ensure the quality of maternal health services and safety of patients while working in inadequate conditions.

\section{Conclusion}

The issue of working condition including inappropriate facility building, hygiene and clean water was perceived as 
the obstacle to maternal service utilisation and provision, and the main reason that most of the $\mathrm{CHCs}$ do not comply with National Guidelines for reproductive health. More importantly, together with other factors such as working environment, distrust from patients, these factors affect HW morale and causes job dissatisfaction, which eventually lower HW motivation and performance. [24] At the national level, there is a need for government action on policies relevant to the health workforce. National policies should give greater attention to enabling factors to attract and retain HWs to remote area health services. This should include a review of not only financial incentives and training opportunities as mentioned in previous reports, but of investment in health facility infrastructure as well. In the long term, investment in remote and disadvantaged areas to improve facility capabilities (e.g. availability of service rooms, clean water, drugs supplies and medical equipment) could enable HWs to perform according to the National Guidelines for reproductive health and also motivate them to work better.

\section{Competing interests}

The authors declare that they have no competing interests.

\section{References}

1. World Health Organisation. Working together for health. Geneva: WHO; 2006.

2. Matsuokaa S, et al. Perceived barriers to utilization of maternal health services in rural Cambodia. Health Policy. 2010;95:255-263.

3. Asatiani T. Assessment of emergency obstetric care in Kosovo. Department of Reproductive Health. Tbilisi Georgia: State Medical University; 2008.

4. Hsia RY, et al. Access to emergency and surgical care in sub-Saharan Africa: the infrastructure gap. Health Policy and Planning. 2012; 10.1093/heapol/czr023:234-244.

5. Vietnamese Ministry of Health and Health Partnership Group. Joint Annual Health Review: human resources for health. Ha Noi; 2009.

6. Vietnamese Ministry of Health and Health Partnership Group. Joint Annual Health Review 2012: improving quality of medical services. Ha Noi; 2012.

7. Willis-Shattuck $M$, et al. Motivation and retention of health workers in developing countries: a systematic review. BMC Health Services Research. 2008;8(247).

8. Dieleman $\mathrm{M}$, et al. Identifying factors for job motivation of rural health workers in North Viet Nam. Human Resources for Health. 2003;1(10).

9. Patton MQ. Qualitative research and evaluation methods. Thousand Oks, California: Sage; 2002.

10. Plano Clark VL, Creswell JW. The mixed methods readers. Thousand Oaks, California: Sage; 2008.

11. Liamputtong P. Qualitative research methods. Melbourne: Oxford University Press; 2008.

12. Creswell JW, editor. Qualitative inquiry and research design: choosing among five approaches. 3rd ed. Sage: Thousand Oaks, California. p. 448.
13. Dieleman $\mathrm{M}$, et al. The match between motivation and performance management of health sector workers in Mali. Human Resources for Health. 2006;4(2).

14. Charmaz K. Constructing grounded theory: a practical guide through qualitative analysis. London: Sage Publications; 2006.

15. Health V Mo. Bộ tiêu chí quốc gia về y tế xã giai đoạn 2011-2020. (Ban hành kèm theo quyết định 3447/QĐ-BYT (National Criteria for assessment of commune health centres period 2011-2020. Issued with Decision No 3447/QD-BYT). Hanoi; 2011.

16. Vietnamese Ministry of Health. Hướng dẫn quốc gia về các dịch vụ chăm sóc sức khỏe sinh sản (Ban hành kèm theo Quyết định số 4620/QĐ-BYT) (National Guideline on Reproductive Health services. Issued with the Decision 4620/QĐ-BYT on 25/11/2009). 2009.

17. Vietnamese Ministry of Health. Assessment report of reproductive health network in 2008. Hanoi, Vietnam; 2009.

18. Rowe AK, et al. How can we achieve and maintain high-quality performance of health workers in low-resource settings? The Lancet. 2005;366:1026-35.

19. Franco LM, Bennett S, Kanfer R. Health sector reform and public sector health worker motivation: a conceptual framework. Soc Sci Med. 2002; 54:1255-1266.

20. Chen $L$, et al. Human resources for health: overcoming the crisis. The Lancet. 2004;364(9449):1984-1990.

21. Parkhurst JO. et al. Health systems factors influencing maternal health services: a four-country comparison. Health Policy. 2005; 73(2):127-138.

22. Chimwaza W, et al. What makes staff consider leaving the health service in Malawi? Human Resources for Health. 2014;12(17).

23. Dieleman M, Gerretsen B, van de Wilt GJ. Human resource management interventions to improve health workers' performance in low and middle income countries: a realist review. Health Research Policy and Systems. 2009;7(7):1-13.

24. Nguyen THT, Wilson A, McDonald F. Motivation or demotivation of health workers providing maternal health services in rural areas in Vietnam: findings from a mixed-methods study. Human Resources for Health. 2015;13(91). 